\title{
Clinical Characteristics of Nystagmus in Albinos Living in Libreville
}

\author{
Prudence Ada Assoumou ${ }^{1,2}$, Tatiana Mba Aki ${ }^{1}$, Olele Oussavou${ }^{2}$, Emmanuel Mve Mengome $^{1}$ \\ ${ }^{1}$ Department of Ophthalmology, Faculty of Medicine, University of Health and Science, Libreville, Gabon \\ ${ }^{2}$ Ophthalmology Department of Agondje University Hospital Center, Libreville, Gabon \\ Email:prudence_apa@yahoo.fr
}

How to cite this paper: Assoumou, P.A., Aki, T.M., Oussavou, O. and Mengome, E.M. (2020) Clinical Characteristics of Nystagmus in Albinos Living in Libreville. Open Journal of Ophthalmology, 10, 69-76. https://doi.org/10.4236/ojoph.2020.101009

Received: December 16, 2019

Accepted: January 5, 2020

Published: January 8, 2020

Copyright $\odot 2020$ by author(s) and Scientific Research Publishing Inc. This work is licensed under the Creative Commons Attribution International License (CC BY 4.0).

http://creativecommons.org/licenses/by/4.0/ (c) (i) Open Access

\begin{abstract}
Introduction: Nystagmus is a static ocular disorder characterized by an oscillatory, involuntary and rhythmic movement of eyes. In Libreville, no data on the subject is available. The purpose of this study is to describe clinical characteristics of nystagmus in albinos living in Libreville. Methods: This is a descriptive, cross-sectional study including 43 albinos with oculocutaneous albinism and nystagmus during the period from February 01, 2017 to February 01,2018 . Variables studied were age, sex, visual acuity, objective refraction, characteristics of the nystagmus including morphology, direction, intensity and associated signs such as stiff neck and squint. Results: The mean age was $21.2 \pm 17$ years with a female-dominated ratio of 0.53 . The visual acuity from afar without correction (AVLSC) was less than $3 / 10$ in $88.4 \%$ of the cases. The most common ametropia was astigmatism in $51.2 \%$ of cases. Nystagmus was present in all albinos. The spring type was found in $69.7 \%$ of cases. The direction was horizontal in $67.4 \%$ of the cases and rotary in $32.6 \%$ of the cases. The intensity was moderate in $55.8 \%$ of cases. The blocking position was the primary near vision position in $69.7 \%$ of the cases. Nystagmus was associated with a stiff neck in $28 \%$ of the cases and strabismus in $48.8 \%$ of the cases. Conclusion: The albinos nystagmus living in Libreville is of the spring type, horizontal direction, of moderate intensity and calmed in the primary position in near vision.
\end{abstract}

\section{Keywords}

Nystagmus, Albinos, Libreville

\section{Introduction}

The nystagmus is a back and forth, rhythmic, incessant and involuntary move- 
ment of both eyes, which is not related to damage of the oculomotor muscles but to an abnormality in the gaze fixation system. This abnormality may be physiological or pathological, and in the latter, the origin is congenital or acquired with sometimes associations with cataracts, strabismus and albinismus which is the most common universal affection of hereditary generalized hypopigmentation, with a worldwide incidence of $1 / 17,000$ to $1 / 20,000$ births and which includes a group of hereditary conditions related to an abnormality of melanin biosynthesis, a pigment produced in specialized cells of the skin, hair, iris, the pigmented epithelium of the retina and inner ear, associated with a normal number and structure of melanocytes [1] [2] [3]. Nystagmus is responsible for decreased visual acuity, astigmatism and torticollis. However, perfect knowledge of its clinical characteristics of this pathology will allow better ophthalmological management of albinos. Literature on the frequency of nystagmus in the general population is scarce. Nevertheless, Von Noorden cites a reference, that of Hemmes GD who had reported a prevalence of $0.07 \%$ during his work [4] [5]. In Libreville, limited data on the subject is available, hence the initiative for this work aims to describe the clinical characteristics of nystagmus in albinos living in Libreville.

\section{Methods}

This was a cross-sectional, descriptive study conducted in the ophthalmology department of the University Hospital Center of Agondje (CHUA) in Libreville from February 01, 2017 to February 01, 2018 (one year). The study population concerned 43 albinos with oculocutaneous albinism and nystagmus from the Association for the Fight for the Wellbeing of Albinos (ALBA) who were identified after a week of awareness raising on ocular pathologies. All albinos of this study were contacted by telephone using the telephone directory made available by the ALBA association for all information about the study in which they would take part.

The inclusion criteria concerned all albinos with oculocutaneous albinism with nystagmus from ALBA within present in Libreville during the study period and who agreed to participate in the study. The exclusion criteria were albinos who didn't belong to ALBA, or were not in Libreville at the time of the study or refused to participate. The albinos selected for the survey were received in a defined order of passage and all were provided a full and free ophthalmological consultation carried out by a medical team made up of an ophthalmologist and an orthoptist. The variables studied related to age, sex, visual acuity, objective refraction, characteristics of the nystagmus, in particular morphology, direction, intensity, blocking position and the associated signs, particularly stiff neck and squint.

The investigation provided information on the age and sex of the albino. The screening helped search for a stiff neck by monitoring the fixation supplemented by the study of oculomotricity in search of strabismus and nystagmus. The 
search for strabismus was done by corneal reflections or Hirshberg reflections. The patient fixing of light point in front of them at $30 \mathrm{~cm}$ the ophthalmologist with an ophthalmoscope, studied the direction of the corneal reflection. When the reflection was centered, there was no squint. When the reflection was nasal, the squint was convergent and when it was temporal, the squint was divergent. However, strabismus was said to be vertical when the corneal reflection was higher or lower. For the torticollis study, the ophthalmologist had to look at the patient from the front, back and perform palpation of the sterno-cleido-mastoid in search of a contracture of this muscle or an abnormal position of the head adopted by the subject to allow binocular vision, an improvement in visual acuity with reduction or complete reduction nystagmus. The ophthalmological examination included the measurement of distant visual acuity without correction in monocular then in binocular. This was done at distance of 5 meters in the standard consultation room with Monell and "E" test projector from Snellen if necessary, enabling visual acuity to be calculated from $1 / 10^{\text {th }}$ to $10 / 10$ e. Patients whose visual acuity were between $8 / 10$ and $10 / 10$ were considered emmetropic and those with visual acuity less than $8 / 10$ were ametropic. All ametropic patients benefited from an objective refraction using an automatic refractometer after instillation of a cycloplegic including atropine eye drops.

The analysis of the nystagmus was done by fixing an optotype in the different directions of the gaze and in convergence. It made it possible to highlight its characteristics, namely its morphology, its direction, its intensity and its blocking position. According to the morphology, the nystagmus was of the pendulum type when the drift phase and the recall phase were at equal speed then of the spring type when the recall phase was faster than the drift phase and of mixed type when it was both pendulum and spring. By convention the direction of the rapid phase was that of the nystagmus. According to the direction, the direction of the nystagmus was variable, one could have at horizontal, vertical, oblique or even rotary beat. Depending on the intensity, the intensity defined as the product of the amplitude and the frequency was classified into three categories; weak, medium and strong. The nystagmus was of weak intensity if it was visible only with the slit lamp then of average intensity when it was visible with the naked eye at distance lower or equal to $3 \mathrm{~m}$ and finally of high intensity when seen beyond $3 \mathrm{~m}$. Depending on the blocking position, blocking zones were found. The primary position coupled with near vision gave more blocking.

All the data collected on the questionnaire was entered in Microsoft Office 2010 Excel and analyzed using the Epi info TM 7.2.0.1 CDC (Center for Disease Control and Prevention) and International Business Machine (IBM) ${ }^{\circledR}$ Statistical Package for the Social Sciences (SPSS) ${ }^{\circ}$. The results were expressed in figures and tables showing the numbers and frequencies. This study was conducted in accordance with the recommendations of the Declaration of ethics of Helsinki on the use of living beings. Informed consent was obtained from participants with respect to confidentiality. 


\section{Results}

The study population involved 43 albinos with oculocutaneous albinism and nystagmus. The average age of the population was 21.2 years with a range of 8 months and 62 years (Figure 1). Females represented $65.1 \%$ of albinos against $34.9 \%$ of males, a female-dominated ratio of 0.5 (Table 1). Visual acuity from afar without correction was less than $3 / 10$ in $88.4 \%$ of cases (Table 2). The most common ametropia was astigmatism in $51.2 \%$ of cases followed by myopia in $32.6 \%$ of cases and hyperopia in $16.2 \%$ of cases (Table 3). Nystagmus was present in all albinos. Morphologically, it was spring type in $69.7 \%$ of cases, then pendulum type in $27.9 \%$ of cases and mixed type in $2.4 \%$ of cases (Table 4 ). The direction of the nystagmus was simple horizontal in $67.4 \%$ of the cases with a rotary component in $32.6 \%$ of the cases (Table 5). The intensity of the nystagmus was variable. It was moderate in $55.8 \%$ of cases, low in $34.8 \%$ of cases and high in $9.4 \%$ of cases (Table 6). The blocking position was the primary and near vision position in $69.7 \%$ of the cases (Table 7). Nystagmus was associated with a stiff neck in $28 \%$ of the cases and strabismus in $48.8 \%$ of the cases.

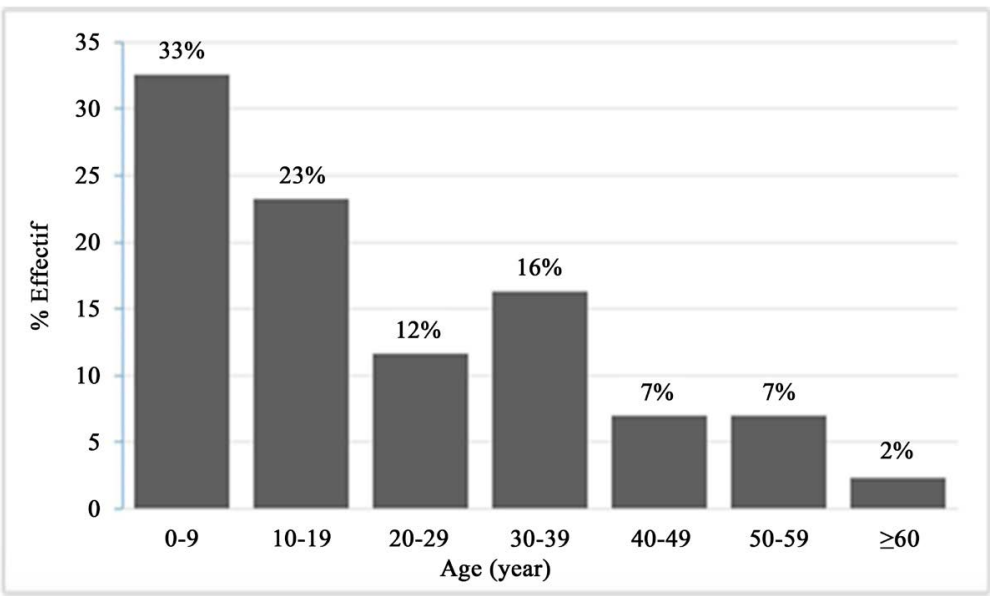

Figure 1. Age distribution of albinos.

Table 1. Distribution of albinos by sex.

\begin{tabular}{cccc}
\hline Sex & Female & Male & TOTAL \\
\hline Number & 28 & 15 & 43 \\
Percentage & 65.1 & 34.9 & 100 \\
\hline
\end{tabular}

Table 2. Visual acuity from afar without correction (AVLSC).

\begin{tabular}{cccc}
\hline AVLSC & $\begin{array}{c}\text { Right Eye } \\
\mathbf{n}(\%)\end{array}$ & $\begin{array}{c}\text { Left Eye } \\
\mathbf{n}(\%)\end{array}$ & $\begin{array}{c}\text { 2 Eyes } \\
\mathbf{n}(\%)\end{array}$ \\
\hline $8-10$ & $0(0)$ & $0(0)$ & $0(0)$ \\
$7-3$ & $5(11.6)$ & $5(11.6)$ & $10(11.6)$ \\
$<3$ & $38(88.4)$ & $38(88.4)$ & $\mathbf{7 6}(88.4)$ \\
TOTAL & $43(100)$ & $43(100)$ & $86(100)$ \\
\hline
\end{tabular}


Table 3. Different ametropias encountered in albinos.

\begin{tabular}{cccc}
\hline Ametropias & $\begin{array}{c}\text { Right Eye } \\
\mathbf{n}(\%)\end{array}$ & $\begin{array}{c}\text { Left Eye } \\
\mathbf{n}(\%)\end{array}$ & $\begin{array}{c}\text { 2 Eyes } \\
\mathbf{n}(\%)\end{array}$ \\
\hline Hyperopia & $7(16.2)$ & $7(16.2)$ & $14(16.2)$ \\
Myopia & $14(32.6)$ & $14(32.6)$ & $28(32.6)$ \\
Astigmatism & $22(51.2)$ & $22(51.2)$ & $\mathbf{4 4}(51.2)$ \\
TOTAL & $43(100)$ & $43(100)$ & $86(100)$ \\
\hline
\end{tabular}

Table 4. Morphology of Nystagmus.

\begin{tabular}{cccc}
\hline Morphology & $\begin{array}{c}\text { Right Eye } \\
\mathrm{n}(\%)\end{array}$ & $\begin{array}{c}\text { Left Eye } \\
\mathrm{n}(\%)\end{array}$ & $\begin{array}{c}\text { 2 Eyes } \\
\mathbf{n}(\%)\end{array}$ \\
\hline On Springs & $30(69.7)$ & $30(69.7)$ & $60(69.7)$ \\
Pendulum & $12(27.9)$ & $12(27.9)$ & $24(27.9)$ \\
Mixed & $1(2.4)$ & $1(2.4)$ & $2(2.4)$ \\
TOTAL & $43(100)$ & $43(100)$ & $86(100)$ \\
\hline
\end{tabular}

Table 5. Direction of Nystagmus.

\begin{tabular}{cccc}
\hline Direction & $\begin{array}{c}\text { Right Eye } \\
\mathbf{n}(\%)\end{array}$ & $\begin{array}{c}\text { Left Eye } \\
\mathbf{n}(\%)\end{array}$ & $\begin{array}{c}\text { 2 Eyes } \\
\mathbf{n}(\%)\end{array}$ \\
\hline Horizontal & $\mathbf{2 9 ( 6 7 . 4 )}$ & $\mathbf{2 9 ( 6 7 . 4 )}$ & $\mathbf{5 8}(67.4)$ \\
Vertical & $0(0)$ & $0(0)$ & $0(0)$ \\
Rotary & $14(32.6)$ & $14(32.6)$ & $28(32.6)$ \\
TOTAL & $43(100)$ & $43(100)$ & $86(100)$ \\
\hline
\end{tabular}

Table 6. Intensity of Nystagmus.

\begin{tabular}{cccc}
\hline Intensity & $\begin{array}{c}\text { Right Eye } \\
\mathbf{n}(\%)\end{array}$ & $\begin{array}{c}\text { Left Eye } \\
\mathbf{n}(\%)\end{array}$ & $\begin{array}{c}\text { 2 Eyes } \\
\mathbf{n}(\%)\end{array}$ \\
\hline Low (Visible at LAF) & $15(34.8)$ & $15(34.8)$ & $30(34.8)$ \\
Moderate (Visible within 3 m) & $\mathbf{2 4 ( 5 5 . 8 )}$ & $\mathbf{2 4 ( 5 5 . 8 )}$ & $\mathbf{4 8 ( 5 5 . 8 )}$ \\
Elevated (Visible at more than 3 m) & $4(9.4)$ & $4(9.4)$ & $8(9.4)$ \\
TOTAL & $43(100)$ & $43(100)$ & $86(100)$ \\
\hline
\end{tabular}

Table 7. Nystagmus Blocking position.

\begin{tabular}{cccc}
\hline Blocking Position & $\begin{array}{c}\text { Right Eye } \\
\text { n (\%) }\end{array}$ & $\begin{array}{c}\text { Left Eye } \\
\mathbf{n}(\%)\end{array}$ & $\begin{array}{c}\text { 2 Eyes } \\
\mathbf{n}(\%)\end{array}$ \\
\hline Primary position (PP) & $4(9.3)$ & $4(9.3)$ & $8(9.3)$ \\
Near Vision (VP) & $9(21)$ & $9(21)$ & $18(21)$ \\
PP + VP & $30(69.7)$ & $30(69.7)$ & $60(69.7)$ \\
TOTAL & $43(100)$ & $43(100)$ & $86(100)$ \\
\hline
\end{tabular}




\section{Discussion}

This survey encountered several limitations, the main one being the low participation or refusal of participation of many albinos to the study despite multiple phone calls, awareness' meetings on ocular pathologies and free ophthalmological consultations. A number of reasons based on socio-cultural beliefs that albinos would be subject to human sacrifice may explain the reduced sample of our population. Despite the explanations of science, albinism remains an anomaly source of fear and anxiety in Africa where albinos, victims of many prejudices are discriminated against, marginalized, forced to drop out of school and suffer physical and moral violence or are even murdered for their organs which are sold at high prices. As a result, they are confronted with a whole range of problems that constitute a hindrance to their personal growth, their school attendance, their social and professional integration and their medical care.

The mean age of the population was 21.2 years with a range of 8 months and 62 years (Figure 1). This figure is close to that of Aboubakar in Cameroon (23.89 years) [6] and Ajose in Nigeria (24.6 years) [7] but differs from that of Gargouri in Tunisia (18 years) [8], Ebana in Cameroon (13.11 years) [9] and Mokaya in Kenya (12.56 \pm 4.16 years) [10]. All these different mean ages found all reflect the young population who, according to the data in literature, see their life expectancy reduced because of the sacrifices and rituals to which they are subjected to certain regions [1] [11]. In our series, the female ratio was 0.5 . This result corroborates those of Aboubakar and Mokaya who had also and respectively found a female-dominated ratio of 0.5 and 0.7 [6] [10]. However, these figures differ from those of Ebana, Kassir, Gargouri, and Ajose, who found a predominantly male ratio respectively of $1.21 ; 1.29 ; 2.1$; and 1.1 [7] [8] [9] [12]. Indeed, these controversial results may be the consequence of the massive participation of women in social, humanitarian actions and even in community life. The best visual acuity by far without correction of less than $3 / 10$ was found in $88.4 \%$ of the cases. These results corroborate those in literature [6] [9] [10] because poor visual acuity is one of the main signs associated with nystagmus [13] [14] [15]. Astigmatism was the most common ametropia in $51.2 \%$ of the cases in our series. Indeed, some authors like Gargouri and Aboubakar [6] [8] had found also astigmatism as the most widespread ametropia among all albinos in their various works.

According to literature, ametropias are constant in nystagmus, but other ametropias such as myopia and hyperopia are also described in albinos with nystagmus. All albinos in our series had nystagmus, other authors such as Ebana, Aboubakar, Mokaya and Aquaron [6] [9] [10] [11] also reported the presence of a nystagmus in all albinos in their series. Nystagmus found in albinism is almost constant and can be met in the first months of the albino's life when it is ample. It increases in glare and decreases with the wearing of optical correction [11]. Nystagmus is due to foveal hypoplasia and other ocular abnormalities frequently encountered in albinism [16]. In our series, nystagmus was spring type 
in $69.7 \%$. Other authors like Kumar had also found spring type nystagmus in $66.7 \%$ of the cases [17], opposite of Aboubakar noted a pendulum type nystagmus in $52.8 \%$ of the cases [6]. In our series, nystagmus was horizontal in $67.4 \%$ of the cases with a rotary factor in $32.6 \%$ of the cases, opposite of Chong GT and Mohammed S who had found nystagmus of horizontal direction in $100 \%$ of the cases [18] [19].

Intensity of the nystagmus was variable. It was moderate in $55.8 \%$ of cases, low in $34.8 \%$ of cases and high in $9.4 \%$ of cases. Nystagmus was calmed in primary position and in near vision in $69.7 \%$ of the cases in our work. Several authors such as Abadi and Von Noorden have also found blocking position in primary position and in near vision in their series [4] [20]. Indeed, the nystagmus is slowed in near vision by the action of convergence. Strabismus was noted in $48.8 \%$ of cases. These results are close to that of Aboubakar [6] in $52.8 \%$ of the cases and departs from Mokaya [10] in 91\% of the cases. Squint encountered in albinism can be explained by anomalies in the distribution of retino-geniculate and geniculo-cortical visual fibers which hinder the development of binocular vision [13] [14]. Torticollis in primary fixation by far was noted in $28 \%$ of the cases in our series. This figure differs from that of Ebana, which reported it in $35.7 \%$ of cases [9]. According to literature, most people with albinism adopt a compensatory head posture which helps reduce nystagmus and improve vision. Variability in morphology of the nystagmus describes different types, namely the horizontal, vertical or mixed torticollis [21].

\section{Conflicts of Interest}

The authors declare no conflicts of interest regarding the publication of this paper.

\section{References}

[1] Rooryck, C., Morice, F., Mortemousque, B., et al. (2007) Le soleil et la peau chez l'enfant: Albinisme. Albinisme oculo-cutané. Annales de Dermatologie et de Vénéréologie, 45, 55-64. https://doi.org/10.1016/S0151-9638(07)89250-7

[2] Hong, E.S., Zabeed, H. and Repacholi, M.H. (2006) Albinism in Africa as Public Health Issue. BMC Public Health, 6, Article No. 212.

http://www.biomedcentral.com/1471-2458/6/212

https://doi.org/10.1186/1471-2458-6-212

[3] King, R.A., Hearing, V.J., Creel, D., et al. (1995) Albinism. In: Scriver, C.R., Beaudet, A.L., Sly, W.S. and Valle, D.V., Eds., The Metabolic and Molecular Basis of Inherited Disease, McGraw-Hill, New York, 4353-4392.

[4] Von Noorden, G.K. and Campos, E.C. (2002) Binocular and Ocular Motility. 6th Edition, Mosby, Maryland Heights, 653 p.

[5] Hemmes, G.D. (1927) Hereditary Nystagmus (Abstract). Doctoral Thesis. Utrecht. American Journal of Ophthalmology, 10, 149.

[6] Aboubakar, H., Dohvoam, V., Ebana Mvogo, S., et al. (2017) Les Caractéristiques du Nystagmus chez le Sujet Albinos Camerounais. Health Sciences and Diseases, 18, 25-28. http://www.hsd-fmsb.org 
[7] Ajose, F.O., et al. (2014) Visual Defect in Oculocutaneous Albinism Is Not Associated with Gross Structural Anomaly. Journal of Clinical \& Experimental Dermatology Research, 5, 228. https://doi.org/10.4172/2155-9554.1000228

[8] Gargouri, S., Kaibi, I., Sakka, M., Abid, I., Sallami, D. and Feki, J. (2017) La prise en charge optique des albinos en Tunisie. Refractive management of albinism in Tunisia. J. I. M. Sfax, 25, 40-44.

[9] Ebana Mvogo, C., Bella Hiag, A.L., Ellong, A. and Metogho Mbarga, B. (1999) Les troubles visuels de l'albinos. Etude hospitalière réalisée à l'hôpital général de Douala. Cahiers Santé, 9, 89.

[10] Mokaya, A.K., Njuguna, W., Ilako, D. and Choskey, P. (2014) Pattern of Ocular Findings in Persons with Albinism in Kenya.

[11] Aquaron, R., et al. (2004) L'Albinisme oculocutané au Maghreb, à propos de 15 observations en Algérie, Maroc et Tunisie. Antropo, 7, 55-61.

[12] Kassir, M. and Dodredingao, D.N. (1998) L'albinisme dans la province du Cameroun: Du diagnostic au conseil génétique. Medecine d Afrique Noire, 4, 57-61.

[13] Buffon, G.L. (1971) De l'homme. Maspero, Paris, 407 (Extrait de l'histoire naturelle, 1749).

[14] Rooryck, C., Roudaut, C., Robine, E., Musebeck, J. and Arveiler, B. (2006) Oculocutaneous Albinism with TYRP1 Gene Mutations in a Caucasian Patient. Pigment Cell Research, 19, 239-242. https://doi.org/10.1111/j.1600-0749.2006.00298.x

[15] Forshew, T., Khaliq, S., Tee, L., Smith, U., Johnson, C.A., Mehdi, S., et al. (2005) Identification of Novel TYR and TYRP1 Mutations in Oculocutaneous Albinism. Clinical Genetics, 68, 182-184. https://doi.org/10.1111/j.1399-0004.2005.00460.x

[16] Duncombe-Poulet, C. (2014) L'albinisme, étiologie fréquente des nystagmus congénitaux. Avril Caen.catherine.duncombepoulet@wanadoo.fr.

[17] Kumar, A., Gottlob, I., et al. (2011) Clinical and Oculomotor Characteristics of Albinism Compared to FRMD7 Associated Infantile Nystagmus. Investigative Ophthalmology \& Visual Science, 52, 2306-2313.

https://doi.org/10.1167/iovs.10-5685

[18] Chong, G.T., Farsiu, S., Freedman, S.F., et al. (2009) Abnormal Foveal Morphology in Ocular Albinism Imaged with Spectral-Domain Optical Coherence Tomography. Archives of Ophthalmology, 127, 37-44. https://doi.org/10.1001/archophthalmol.2008.550

[19] Mohammed, S., Gottlob, I., Sheth, V., et al. (2015) Characterization of Abnormal Optic Head Morphology in Albinism Using Optical Coherence Tomography. Investigative Ophthalmology \& Visual Science, 56, 4611-4618. https://doi.org/10.1167/iovs.15-16856

[20] Abadi, R.V. and Dickinson, C.M. (1983) Monochromatic Fund Us Photography of Human Albinos. Archives of Ophthalmology, 101, 1706-1711. https://doi.org/10.1001/archopht.1983.01040020708008

[21] Gassama, M. (2008) Aspects Epidemio-Cliniques et prise en charge dermatologique des albinos dans le service de dermato-vénéréologie du Cnam (Ex Institut Marchoux). Thèse, Bamako, 24-49. 